\title{
DA (IN)TRADUZIBILIDADE: A PROPÓSITO DE PAUL RICOEUR
}

\section{Ivone C. Benedetti}

\begin{abstract}
RESUMO: Este artigo inspira-se num opúsculo de Paul Ricoeur, chamado Sur la traduction. O objetivo destes comentários é não só difundir o pensamento de Ricoeur sobre o assunto, mas também abordá-lo de um ponto de vista crítico, analisando a relação original-tradução a partir de diversas noções de identidade.
\end{abstract}

UNITERMOS: Ricoeur; relações; texto original; tradução; identidade.

RÉSUMÉ: Le présent article s'inspire d'un petit ouvrage de Paul Ricoeur, nommé Sur la traduction. Le but des commentaires cidessous est non seulement de diffuser la pensée de Ricoeur sur ce sujet, mais aussi d'en faire une approche critique, en étudiant les rapports entre le texte-source et la traduction à l'aide des diverses notions d'identité.

MOTS-CLÉS: Ricoeur; rapports; texte-source; traduction; identité.

A obra em questão é constituída por três ensaios. O primeiro, "Défi et bonheur de la traduction", consiste num discurso proferido no Instituto Histórico Alemão em 15 de abril de 1977; o segundo, "Le paradigme de la traduction", é uma aula inaugural apresentada na Faculdade de Teologia Protestante de Paris, em outubro de 1988, publicada em Esprit (n ${ }^{\circ}$ 853, de junho de 1999); o terceiro intitula-se "Um 'passage': traduire l'intraduisible" e é publicado nessa obra pela primeira vez.

Tudo indica que o núcleo do pensamento de Ricoeur sobre o assunto é constituído pela reflexão em torno da traduzibilidade ou intraduzibilidade entre as diversas linguas. Vou tentar fazer um resumo das diversas considerações em torno desse núcleo, presentes nos três ensaios acima enumerados. 
Ricoeur começa dizendo que traduzir é servir dois senhores: um deles é o autor, o outro é o leitor. Esses dois senhores representam dois pólos. De um lado, temos a resistência do leitor, com sua pretensão à auto-suficiência, com sua recusa à mediação do estrangeiro; segundo Ricoeur, essa atitude pode levar ao etnocentrismo e à pretensão de hegemonia cultural. No outro pólo, encontra-se a resistência do próprio texto ao trabalho de tradução. Isto porque o tradutor pretende uma tradução perfeita e, apesar disso, depara-se freqüentemente com ilhas ${ }^{1}$ de intraduzibilidade. Para chegar à conclusão de que a intraduzibilidade é um fato esperável, Ricoeur parte da constatação de que entre duas línguas não só os sistemas lexicais não se superpõem ${ }^{2}$ como também as sintaxes não são equivalentes. Segundo ele, a insatisfação causada pela impossibilidade de atingir a tradução perfeita acaba por dar oportunidade à retradução. Uma solução para esse impasse pode ser buscada na ambição de trazer à tona a face oculta da língua de partida e de desprovincializar a língua materna, convidada a pensar-se como lingua entre outras. Outra solução buscada estaria no sonho de constituir a biblioteca total e a língua universal. É importante notar que essas duas soluções não são propugnadas por Ricoeur; constituem um levantamento daquilo que os tradutores têm feito ou desejado ao longo do tempo. O que Ricoeur afirma é que na renúncia à tradução absoluta está realmente a ventura (le bonheur) da tradução, compensação às desventuras acima enumeradas. A ventura de traduzir é um ganho quando, ligada à perda do absoluto da língua, aceita a distância entre adequação e equivalência. A ventura pode ser encontrada na hospitalidade da língua.

Esses são os principais conceitos que Ricoeur desenvolve nesse primeiro ensaio em torno da questão traduzibilidade/in-

\footnotetext{
1 O grifo é meu. A intenção é ressaltar que Ricoeur não afirma a intraduzibilidade absoluta em seu primeiro ensaio, embora pareça especular sobre ela nos outros dois ensaios.

2 Note-se que ele não afirma a ausência de sobreposições palavra por palavra, mas sim a ausência de coincidência entre os conjuntos de significados de palavras equivalentes em duas linguas. Nos termos de Mounin (Les problèmes théoriques de la traduction, Gallimard, 1963, p. 92), as interrelações que constituem um campo semântico em duas linguas diferentes não são coordenadas.
}

TradTerm, 12, 2006, p. 33-54 
traduzibilidade, conceitos que serão ainda mais desenvolvidos nos outros dois, sobretudo em "Paradigme de la traduction", no qual o autor parece ter atingido maior maturidade nas suas reflexões em torno da tradução.

O segundo ensaio é uma verdadeira homenagem a Antoine Berman. Além disso, Ricoeur cita muito George Steiner, em sua visão da tradução como interpretação. Menciona diversas vezes a frase de Steiner "compreender é traduzir". Nele, o autor volta a tratar daquilo que considerei ser o núcleo do seu pensamento, ou seja, a aparente impossibilidade de tradução (aqui tomada em termos absolutos, e não mais como ilhas de intraduzibilidade), desmentida pela realidade da tradução desde os mais remotos tempos. Ricoeur diz que existe uma "alternativa paralisante" (p. 25-26): ou a diversidade das línguas exprime uma heterogeneidade radical - e então a tradução é teoricamente impossivel, e as línguas são a priori intraduziveis umas pelas outras -, ou a tradução, tomada como fato, é explicada por um fundo comum que a possibilita - mas nesse caso devemos encontrar esse fundo comum, e essa é a pista da língua originária, ou ainda reconstruí-lo logicamente, e essa é a pista da língua universal. Logo, em vista da "heterogeneidade radical" entre as linguas, existem várias possibilidades: uma delas seria a da busca de uma língua originária; a segunda seria a da busca de uma língua universal; a terceira seria desistir da tradução perfeita.

A primeira alternativa, a da busca da língua originária, de acordo com o próprio Ricouer, foi professada por diversas gnoses, pela cabala e pelos hermetistas. Segundo ele, chegou a "produzir frutos venenosos", como o da pretensa língua ariana, mas, na outra vertente - positiva -, estaria Walter Benjamin. Infelizmente, "a prática da tradução não recebe socorro algum dessa nostalgia revertida em esperança escatológica” (p. 29-30). ${ }^{3}$

Mais resistente seria a versão da busca de unidade não em direção a uma origem no tempo, porém em direção a objetivos utópicos, a línguas artificiais, códigos construídos a priori, com

3 Não deixa de ser interessante o caráter dúplice, captado por Ricoeur, do mesmo desejo de se chegar à língua originária: de um lado, a pureza totalitária, de outro a brandura reflexiva de Benjamin. 
o objetivo de eliminar as imperfeições das línguas naturais. Essa tentativa sempre malogrou, pois atingiu sucesso parcial na sintaxe e fracasso total no léxico e na morfologia. Isto porque "não há acordo sobre o que caracterizaria a língua perfeita no plano do léxico; esse acordo pressupõe homologia completa entre signo e coisa, sem arbitrariedade" (p. 30-32).

A terceira possibilidade seria a da renúncia à tradução perfeita; assim, no terceiro ensaio, Ricoeur acaba retomando a noção já esboçada no primeiro e no segundo, ou seja, a da renúncia à perfeição, o que parece ser um Leitmotiv de sua reflexão sobre o assunto.

Esse apanhado poderia ser assim esquematizado:

1. A tradução choca-se com dois obstáculos, duas resistências: a do leitor (a aceitar o estrangeiro), a do próprio texto (a revelar-se por inteiro). No leitor, atua o etnocentrismo; no texto, a não-superposição dos sistemas lexicais e da sintaxe.

2. Para superar esse impasse, em todos os tempos, foram idealizadas algumas soluções:

a. a da lingua primordial;

b. a da lingua ideal.

Ambas são impossiveis de atingir. Em vista dessa impossibilidade, a solução estaria na não-solução: na renúncia à tradução perfeita.

Para explicar as dificuldades inerentes ao processo, Ricoeur recorre à analogia entre as dificuldades da tradução e as dificuldades de compreensão entre os falantes de uma mesma língua. Procura então discernir o que prejudica a comunicação. Diz que, "partindo do fato maciço que caracteriza nossas línguas, é sempre possivel dizer a mesma coisa de outro modo (p. 45, grifo do autor)". Diz ele que é isso o que fazemos quando definimos uma palavra com outra do mesmo léxico, como nos dicionários. E, dizendo tais coisas, Ricoeur desemboca na seguinte afirmação: "Deparamos assim, dentro de nossa comunidade lingüística, o mesmo enigma do mesmo, da significação mesma, o inencontrável sentido idêntico, que consideremos capaz de tornar equivalentes as duas versões da mesma afirmação" (p. 45, grifo meu). Essa seria também, segundo ele, a realidade da tradução. 
Ora, dizer o mesmo de formas diferentes nunca é o mesmo dizer, mas outro.

Ter-se-ia, então, como desdobramento: é preciso renunciar ao ideal de tradução perfeita porque nunca se diz o mesmo com palavras diferentes. O "mesmo" (ideal buscado em tradução) está, portanto, fadado a ser buscado incessantemente. Nunca será alcançado, porque alcançá-lo de outro modo que não seja o de sua própria enunciação é uma contradição: o mesmo só é igual a si mesmo. E tudo o que busca ser o mesmo não passa de imitação.

Aî há material para muita discussão. Esquematizando:

1. A procura de dizer o mesmo de outro modo é infrutífera devido à radical heterogeneidade entre as línguas - isso leva à tese da intraduzibilidade fundamental.

2. Esse malogro leva à construção de comparáveis, das equivalências não-idênticas (que podem ser múltiplas), pois o mesmo é único - as várias tentativas propiciam retraduções.

Vejo aí uma aporia, em cuja base estaria a fugacidade do conceito de identidade. Ricoeur fala em inencontrável sentido idêntico. A que tipo de identidade se refere? A que conceito de identidade, aliás, sempre se alude quando se fala em identidade entre original e tradução?

Ao de unidade? Segundo esse conceito (aristotélico), as coisas são idênticas no mesmo sentido em que são unas, já que são idênticas quando é uma só sua matéria (em espécie ou em número) ou quando sua substância é una. Identidade é, de algum modo, unidade, quer a unidade se refira a mais de uma coisa, quer se refira a uma única coisa, considerada como duas, tal como acontece quando se diz que a coisa é idêntica a si mesma.

Ao de igualdade (leibniziano)? Idênticas são as coisas que se podem substituir uma à outra salva veritate. Se $A$ estiver contido numa proposição verdadeira e se, pondo-se $B$ no lugar de $A$, a proposição resultante continuar sendo verdadeira, e se o mesmo acontecer em qualquer outra proposição, diz-se que $A$ e $B$ são idênticos; reciprocamente, se $A$ e $B$ são idênticos, a substituição a que nos referimos pode acontecer. 
Ou a uma terceira concepção, de convencionalidade? Para ela, a identidade pode ser estabelecida ou reconhecida com base em qualquer critério convencional. De acordo com esta concepção, não é possível estabelecer em definitivo o significado da identidade ou o critério para reconhecê-la, mas, dentro de determinado sistema lingüístico, é possivel determinar esse critério de forma convencional, porém oportuna. Essa concepção foi apresentada por F. Waismann num artigo de 1936 ("Über den Begriff der Identität”, em Erkenntniss, VI, p. 56 ss.), em polêmica aberta contra a definição carnapiana de identidade [Carnap adotava a concepção de Leibniz]; foi representada por P. T. Geach (em oposição a Quine), segundo o qual, quando se diz ' $x$ é idêntico a $y$ ', tem-se uma expressão incompleta, abreviativa de ' $x$ é o mesmo $A$ que $y$ ', onde ' $A$ ' é um nome cujo significado resulta do contexto ("Identity", em Rev. of Met., 1967, p. 2-12, apud Abbagnano)".

O tipo de identidade como unidade (Aristóteles) é impossível em tradução. Porque em tradução a "matéria" (digamos, os significantes) 4 não é a mesma. Quanto à "substância" (os significados, o sentido), ${ }^{5}$ talvez muitos acreditem que, em tradução, é possivel construir uma identidade nos termos aristotélicos (= unidade). Isso equivaleria, por exemplo, à inexistência de "ilhas de intraduzibilidade". Como se sabe, nem sempre essa esperança tem condições de realizar-se, em vista dos eventuais desfoques lexicais, das inúmeras vicissitudes sintáticas e não-coincidências culturais, principais pedras nesse caminho. Ou seja: não há sobreposição dos sistemas lexicais (nos termos de Ricoeur), e as sintaxes não são as mesmas: essas discrepâncias "materiais" impediriam que se atingisse uma "unidade substancial". Enfim, não há unidade alguma de "matéria" entre o texto traduzido e o original, e nem sempre há entre eles unidade de "substância". Tentar enquadrar a tradução nesse conceito de identidade leva à conclusão da sua inviabilidade.

Quanto à concepção leibniziana, parece ter grande vigência na prática da tradução. Exemplificaria da seguinte maneira:

No sentido de forma ou corpo.

Aqui, adaptando o conceito aristotélico de substância: aquilo que é para sempre, aquilo que é necessariamente.

TradTerm, 12, 2006, p. 33-54 
as expressões Sr. Luís Inácio da Silva $\left[\mathrm{E}_{1}\right]$ e Lula $\left[\mathrm{E}_{2}\right]$ seriam idênticas, pois a substituição de uma pela outra na proposição $E_{1} / E_{2}$ foi eleito presidente do Brasil em 2002 não afeta seu caráter de verdade. Estamos diante daquilo que ordinariamente se enquadra no campo da sinonímia. Em tradução, porém, essa questão está longe de ser banal: parece ser ela um campo no qual se tornam muito agudas as questões mais complexas desse tipo de estudo. Transpondo esse conceito de identidade para a tradução, seria possível dizer que, se, pondo o texto traduzido $T_{t}$ no lugar do texto original $\mathrm{T}_{\mathrm{o}}$, tivermos sempre proposições com $\mathrm{o}$ mesmo significado (se for a mesma a relação que $T_{t}$ e $T_{o}$ mantêm com o referente, por exemplo), então teremos identidade entre $T_{t}$ e $\mathrm{T}_{\text {. }}$. Enfim, segundo essa concepção, é preciso usar como parâmetro um terceiro elemento para estabelecer a "verdade do texto traduzido". Esse terceiro elemento seria o designatum. ${ }^{6}$ Assim, em português as frases Luís Inácio da Silva é presidente do Brasil e Lula é presidente do Brasil constituiriam uma identidade. De modo semelhante, o tradutor inglês que usasse Mr. Silva em lugar de Lula, ou de Luís Inácio da Silva, se valeria desse mesmo conceito de identidade, e a tradução estaria justificada. Esse expediente é freqüentíssimo em tradução.

Mas aí se pode fazer uma objeção. Porque, embora a "expressão $a$ ", Mr. Silva, e a "expressão b", Lula, remetam ao mesmo referente, as duas não se equivalem totalmente porque pertencem a registros diferentes, ou seja, o grau de familiaridade que cada uma transmite em sua cultura de origem não é o mesmo. Teríamos então um tipo de identidade insuficiente ou discutivel em tradução, pois implicaria uma mudança no registro do discurso, em que se passaria de um tom coloquial a um tom formal. Esse tipo de mudança de acidente pode ser substancial em tradução, pois o uso de uma expressão ou de outra transmite representações diferentes sobre a mesma personagem por parte de grupos diferentes de indivíduos. Enfim, o uso de uma por outra mudaria o foco da enunciação, e, em certas situações, o recurso a essas permutas poderia levar o leitor a atribuir o

\footnotetext{
6 Prefiro o conceito de designatum a referente, pois na tradução entram em jogo também processos e qualidades, além de nomes.
} 
enunciado, subliminarmente, a diferentes tipos de enunciador. Essa objeção poderia ser explicada da seguinte forma: a expressão $a$ e a expressão $b$ mantêm com o referente o mesmo tipo de relação objetiva, mas não o mesmo tipo de relação subjetiva. E essa falta de identidade, em tradução, pode ter conseqüências indesejáveis.

Aplicando-se o mesmo exemplo à terceira visão, contextual, seria possivel dizer, por exemplo, que a identidade entre as frases Luís Inácio da Silva é presidente do Brasil e Lula é presidente do Brasil só é válida no contexto histórico brasileiro do fim do século XX e do começo do XXI - isso em termos extratextuais, pois é preciso considerar também as relações intrinsecamente textuais. Desse ponto de vista, a identidade estabelecida entre Lula e Mr. Silva pelo tradutor inglês poderá ser considerada legítima por quem argumentar que, no contexto lingüístico-cultural em que ele atua, o uso de "Lula" poderia eventualmente causar ininteligibilidade ou perplexidade. A substituição, portanto, teria em vista evitar um choque cultural.

Como vemos, é muito provável que as teses de traduzibilidade ou intraduzibilidade se baseiem, alternadamente, em diversos conceitos de identidade, nem sempre explicitados e freqüentemente não conscientizados. $\mathrm{E}$ - o mais importante - esses mesmos conceitos estão operantes na mente do tradutor (conscientemente ou não) no momento de suas escolhas. É essa flutuação que, entre outras coisas, produz teses díspares, como a da maior importância conferida ao texto-fonte (de partida) ou ao texto de destino (de chegada).

Para concluir este raciocínio, uma pergunta: até que ponto o tradutor inglês é livre para estabelecer, no caso do exemplo citado, identidade "de matéria" (em termos aristotélicos) e ensinar a seus leitores quem é Lula? Resposta: isso também depende do seu contexto de atuação.

Porque a tradução é feita, por excelência, entre textos escritos em contextos culturais diferentes. Qual desses contextos levar em conta e quando? Inversamente, se num jornal escrito em língua inglesa tivermos "Mr. Bush", a que contexto deveremos dar maior peso numa tradução para o português: ao da língua de origem, e usar Sr. Bush, ou ao da língua de chegada, e 
usar Bush? Como se vê, não estamos aí diante de um problema de intraduzibilidade, mas de um problema de estabelecimento de critérios para a identidade em tradução.

Muitas vezes, é aí que se situa o problema da tradução: na dificuldade em estabelecer com precisão o tom do discurso, em transmitir com exatidão (e não tanto em captar com certeza) a representação (como conceito e/ou idéia) contida no texto.

Diante do que se expôs acima, é fácil deduzir que a busca do mesmo é infrutífera. E aí é preciso fazer mais algumas especificações. Cabe distinguir dois mesmos: a) um consubstanciado na fórmula "tradução = original" (e, nesse sentido, é preciso esclarecer que conceito de identidade se está levando em conta, como vimos acima) e b) um outro mesmo, consubstanciado na fórmula "tradução A = tradução B". Se não é tão difícil entender as dificuldades de identidade entre, de um lado, traduções $A, B, C \ldots n$ e, de outro, o texto original, mais dificil é entender a dificuldade de atingir uma identidade idealizada entre as várias traduções de um mesmo texto numa mesma língua $(A, B$, $C \ldots n)$. O que não deixa de constituir uma espécie de antinomia porque, da pressuposição (correta) de uma identidade de língua (sempre) e de contexto cultural (freqüentemente) entre as várias traduções, não se chega, na realidade, a uma esperada identidade "de matéria" entre elas. Assim, a busca da identidade a), idealizada, traria como conseqüência necessária a retradução, que, na visão de Ricoeur, representa as reiteradas tentativas de atingir aquela identidade: diante do fracasso de alguém, sempre haverá quem faça outra tentativa. E - acrescento - na retradução constata-se a impossibilidade de atingir a identidade b) (o que, de certo modo, contraria as expectativas).

A conclusão é previsivel: se não é possível a identidade, devemos nos contentar com a equivalência não-idêntica (p. 63). Assim, parte-se da busca de uma identidade absoluta que, não atingida, justifica a resignação à não-identidade.

A alternativa que proponho é, portanto, diferente: a) flexibilizar o conceito de identidade em tradução e, conseqüentemente, b) deixar de raciocinar em termos de terceiro excluído, ou seja: não haveria contradição em afirmar que o texto $T_{t}$ é $T_{o} e$ não-T ao mesmo tempo. 
Uma primeira medida para sair da aporia seria relativizar as afirmações, buscando sempre respaldá-las na realidade. Realmente, é justificável falar em intraduzibilidade quando se tem em mente a tradução dita "literária". Fora dela, esse conceito começa a perder vigor, ainda que não deixe de existir. Acredito que o fator mais determinante dessa mudança está no cunho universalista ou particularista do texto. Exemplifico. Os textos de medicina costumam ser "universalistas". A medicina visa a um objeto (o corpo humano) que é igual em todo o planeta. Além disso, em vista da globalização, é grande a possibilidade de se citarem medicamentos e intervenções conhecidas por todos os profissionais da área, pelo menos no contexto ocidental. Ao contrário, um campo de estudo que costuma conter forte cunho particularista é o direito. Freqüentemente, não é possivel encontrar coincidência entre instituições. Como se vê, dependendo também da área de estudo, é maior ou menor a freqüência com que se incorre em situações de intraduzibilidade.

Repito, então, que o que está aí em jogo é um critério de definição. Quando se defende a fundamental intraduzibilidade entre as linguas e logo depois se é obrigado a constatar que, apesar dessa premissa, a tradução existe, parece claro que, sem se notar, se está fazendo referência a duas imagens diferentes de tradução. Uma seria a tradução ideal, nunca concretizada; a outra seria a tradução real, aquela que é posta em prática há milênios e que, há milênios, consegue fazer que os diversos grupos humanos se entendam. E a história mostra que (salvo momentos anedóticos) a tradução sempre possibilitou o entendimento dos homens em torno de seus desentendimentos ditados por conflitos de interesse.

Mas talvez seja possivel responder a Ricoeur com o próprio Ricoeur. Tentemos.

Desenvolvendo seu raciocínio, Ricoeur se pergunta:

"Com que trabalhamos quando falamos e dirigimos a palavra a outrem?" E responde: “com três tipos de unidade: as palavras, ou seja, os signos que encontramos no léxico; com as frases, para as quais não há léxico [...] e com os textos, ou seja, seqüências de frases. [...] esses três tipos de unidade [...] são a fonte do distanciamento em 
relação a uma suposta língua perfeita e fonte de mal-entendido no uso cotidiano; por esse motivo, há ensejo para interpretações múltiplas e concorrentes” (p. 46-47).

E, continuando a desenvolver seu raciocínio, vão sendo traçados os caminhos para solucionar essa perplexidade. Na p. 47, ao tratar de polissemia ${ }^{7}$ e contexto, diz Ricoeur que o sentido é cada vez delimitado pelo uso, que consiste essencialmente em selecionar a parte do sentido da palavra que convém ao resto da frase e colabora com este para a unidade do sentido expresso e oferecido ao intercâmbio. É a cada vez o contexto que decide o sentido assumido pela palavra em determinada circunstância do discurso. É assim que, não sem caráter paradoxal, os mesmos elementos que "são fonte do distanciamento em relação a uma suposta língua perfeita e fonte de mal-entendido no cotidiano" são justamente os que dirimem as dúvidas eventualmente suscitadas pela presença de palavras polissêmicas. Ora, de que é feito o contexto? O contexto é feito justamente da interrelação entre palavras e frases. Nele também entram elementos extralingüísticos, pressupostos, conotações etc., enfim, dados que constituem o universo cultural dos interlocutores ou do tradutor e o universo cultural do próprio texto, aquilo que o seu autor traz à baila, pressupõe ou oculta no momento em que o escreve.

Minha impressão é de que Ricoeur traz à tona elementos riquíssimos, mas se limita a deixá-los diante de nossos olhos, sem tentar uma sintese. Também tenho a impressão de que ele flutua entre idéias legadas por um sistema e a busca de soluções não sistemáticas. Dessa flutuação, porém, não sai. Seus três ensaios constituem mais a apresentação de questões do que propriamente a exposição ou a proposta de soluções.

Tratando do contexto, Ricoeur diz que

"passamos da palavra à frase - primeira unidade do discurso. A palavra é da alçada da unidade do signo [...] traz consigo novas fontes de ambigüidade, sobretudo no que

7 "Nossas palavras têm mais de um sentido, como se vê nos dicionários. A isso se dá o nome de polissemia". 
se refere à relação entre significado e referente [...]. Os textos são texturas que tecem o discurso em seqüências maiores ou menores" (p. 47-48, grifo do autor).

O ensaio "Paradigme de la traduction" termina com uma tentativa de resposta à seguinte pergunta: "deve-se traduzir o sentido ou traduzir as palavras?". Como disse no princípio, esse ensaio é uma verdadeira homenagem a Berman. Assim sendo, Ricoeur não poderia dar a essa pergunta a resposta "traduzir o sentido". Todos sabemos que Berman era defensor da tradução da letra. É célebre o seu axioma "fidelidade só à letra". E aqui caímos num paradoxo. Se é o contexto que elucida a palavra, a fidelidade à letra, e apenas à letra, não é um contra-senso? Porque as interações sintagmáticas e os jogos paradigmáticos, capazes de desencadear uma miriade de idéias, imagens, lembranças, possibilidades, tornando o texto uma realidade de temível complexidade, também são capazes de, através exatamente da complexidade que criam, lançar luzes sobre palavras ou expressões que, isoladamente, seriam obscuras. E trata-se de uma elucidação que não vai só do contexto à palavra, mas também desta àquele. Ou, como diz Umberto Eco (2000: 243):

É empobrecedor considerar a relação entre palavra e contexto como uma determinação de sentido único, em que o contexto precedente restringe as escolhas lexicais e seleciona os termos apropriados, definindo suas condições de uso. Mas freqüentemente a determinação é invertida, cabendo ao termo estabelecer e definir o contexto. A relação entre termo e contexto é uma relação de sentido duplo, do contexto para o termo e do termo para o contexto. Até porque $[\ldots]$ todo termo aciona, em virtude de sua representação enciclopédica, um complexo quadro de referência, e o semema pode ser visto como um texto virtual.

Temivel ou consoladora essa realidade para o tradutor? Depende. Temivel, demasiado temível num caso, por exemplo, como este, do conto A hora da estrela, de Clarice Lispector: ${ }^{8}$

8 Edit. José Olympio, Rio de Janeiro, 1977, p. 74-75.

TradTerm, 12, 2006, p. 33-54 
- Por que é que você me pede tanta aspirina? Não estou reclamando, embora isso custe dinheiro.

- É para eu não me doer.

- Como é que é? Hein? Você se dói?

- Eu me dôo o tempo todo.

- Aonde?

- Dentro, não sei explicar.

Neste trecho, eu me dôo ilumina com uma luz nova todo o contexto. O uso de uma homofonia (jogo entre a primeira pessoa do presente do indicativo de doer-se e a de doar-se), na pena de um escritor do quilate de Clarice Lispector nunca deverá ser considerado gratuito. Evidentemente, as luzes que essa palavra lança sobre o restante do contexto serão apagadas na tradução que não consiga transportar esse jogo para a outra língua (eis ai um novo conceito de identidade em tradução, que mereceria comentários não cabíveis aqui). Mas o jogo, aí, só tem validade em vista do relativo isolamento da frase Eu me dôo o tempo todo e também porque o modificador "o tempo todo" vem reforçar a hipótese de a personagem estar aventando também o significado relativo a doar-se, além de doer-se. A pergunta feita pela interlocutora (Aonde?) dá a entender que a conjectura só estaria na mente de Macabea, e não na dela. Assim, é preciso que a frase seja parcialmente descontextualizada, para lançar luzes sobre o contexto. Uma frase mais contextualizada como, por exemplo, Eu me dôo muito quando ele fala mal de meu pai dificilmente levaria a essa conjectura.

Todas essas questões de interpretação (e dos elementos que estabelecem seus limites) entram em jogo no ato da tradução. ${ }^{9}$

Mas, voltando às considerações de Ricoeur sobre o contexto, é notável que ele chame de "temivel" (p. 55) o fato de as frases serem pequenos discursos extraídos de discursos mais longos que são os textos (o tradutor sabe bem disso: o que ele traduz são textos, não frases nem palavras). E Ricoeur continua:

9 Sobre o assunto, v. Eco, Limites da interpretação (dados na bibliografia). 
"e os textos, por sua vez, fazem parte de conjuntos culturais através dos quais se exprimem visões de mundo diferentes, que, aliás, podem confrontar-se no interior do mesmo sistema elementar de recorte fonológico, lexical e sintático, a ponto de fazer daquilo que se chama de cultura nacional ou comunitária uma rede de visões de mundo em competição disfarçada ou aberta".

Essas considerações levam Ricoeur a dizer que a tarefa do tradutor não vai da palavra à frase, ao texto, ao conjunto cultural, mas o contrário:

"impregnando-se, por meio de amplas leituras, do espírito de outra cultura, o tradutor desce de volta ao texto, à frase e à palavra. O último ato, se assim se pode dizer, a última decisão, diz respeito ao estabelecimento de um glossário no nivel das palavras" (p. 56).

Assim o "temível recorte" da realidade é justamente a salvação do tradutor. Todo tradutor acha mesmo "temível" o encontro de palavras desvinculadas do contexto. Pois a falta do contexto abre para cada palavra um leque de possibilidades que, em determinadas circunstâncias, pode tornar o texto indecidivel.

No terceiro ensaio, intitulado "Un 'passage': traduire l'intraduisible", Ricoeur retoma o paradoxo do caráter intraduzivel de uma mensagem verbal de uma lingua a outra. Volta a falar da "heterogeneidade radical que deveria (grifo meu) a priori impossibilitar a tradução”. Porque:

1. Os sistemas fonéticos são diferentes.

2. Os sistemas lexicais são diferentes.

3. Os sistemas sintáticos são diferentes.

A isso Ricoeur acrescenta que

"as línguas são diferentes não só no modo de recortar a realidade, mas também no de recompô-la no discurso. Nesse sentido, Benveniste, replicando a Saussure, observa que a primeira unidade da linguagem significante é a frase, e não a palavra, cujo caráter opositivo já lembramos" (p. 54).

TRADTERM, 12, 2006, p. 33-54 
Ricoeur continua desenvolvendo esse raciocínio e diz que a frase organiza de maneira sintética um locutor, um interlocutor, uma mensagem que quer significar alguma coisa, e um referente, ou seja, aquilo sobre o que se fala ("alguém diz algo a alguém sobre algo segundo regras de significância”) (p. 54-55).

Há, nesse trecho e num outro, citado acima, sobre a "homologia completa entre signo e coisa, sem arbitrariedade", dados riquíssimos para uma reflexão complexa. Visto que Ricoeur recorre a Benveniste, a ele também eu recorri. E aqui não há como deixar de estabelecer um vínculo entre arbitrariedade e convencionalidade. Trago essas questões à baila, porque a noção de referente está intimamente ligada a elas, e essa relação merece mais reflexões.

Quando se fala da arbitrariedade do signo, pelo menos nos estudos de tradução, deixa-se de mencionar a interessante questão levantada por Benveniste (1995: 53-59). Entre outras coisas, diz ele que Saussure, para explicar a arbitrariedade do signo, é obrigado a lançar mão da "coisa", o que constitui uma falha metodológica, pois, uma vez que a lingüística é a ciência da forma, e não da substância, para a compreensão do signo seria preciso prescindir da substância e recorrer apenas à forma. Essa crítica se completa com o comentário de que é só pensando na substância que se tem base para julgar arbitrária a natureza do signo, e que foi só argumentando sobre a existência de várias palavras diferentes nas várias línguas (grifo meu) para designar uma mesma realidade que Saussure estabeleceu a arbitrariedade do signo.

Esse mesmo recurso a línguas diferentes para estabelecer o conceito de arbitrariedade já me parece razão para uma primeira reflexão sobre a tradução. Pois a tradução é exatamente aquela atividade que consiste em encontrar numa língua $\mathrm{B}$ o signo que representa um mesmo conceito explicitado numa língua A. Em outras palavras, consiste em traduzir boeuf por boi. Não só isso, pois também consiste em encontrar em outra língua a palavra que traduza eu me dôo de tal maneira que desperte no falante dessa outra língua as duas possibilidades de interpretação que a expressão tem em português. A traduzibilidade, portanto, está ligada ao conhecimento do referente a que o texto 
em questão remete (como no primeiro caso), ou à presença, na língua $\mathrm{B}$, de coincidência entre dois conceitos diferentes para uma mesma forma, tal qual ocorre na língua A (é o segundo caso). No primeiro, não é possível ignorar o referente (vício, aliás, no qual incide amiúde a teorização em torno da tradução); no segundo, não é possivel deixar de fazer uma análise textual e contextual para estudar a pertinência das potenciais interpretações.

A segunda consideração é que, uma vez adquirido o conceito antes inexistente em determinada língua, é inelutável que se adquira o signo, visto que essas duas faces nunca estão separadas (é célebre a analogia entre o signo e a folha de papel, feita por Saussure: o verso e o reverso nunca estão separados). E, assim, a tradução se mostra como processo criativo e ininterrupto: para o conceito presente na língua $A$, mas ainda ausente na língua $\mathrm{B}$, o tradutor desta é obrigado a criar um signo tão logo o conceito passe a existir para a sua comunidade (e tradutor aí está para qualquer falante da língua B). Pode ocorrer que esse signo na língua $B$ não cubra todos os conceitos que o signo correspondente cobre na língua $\mathrm{A}$ - nas áreas de não-sobreposição, haverá intraduzibilidade. E assim voltamos à questão da identidade.

É a essa questão que retorno agora porque ela me servirá de ponte para passar ao assunto "retradução". Mas aqui tratarei dele brevemente, sem entrar em considerações de ordem prática, como os aspectos mercadológicos implicados em qualquer decisão de publicação de retradução por parte de uma editora.

Como vimos, para transpor o obstáculo ("e mesmo a objeção teórica") da intraduzibilidade de princípio de uma língua a outra, Ricoeur conclui que a solução para essa pergunta só pode estar na equivalência sem identidade.

Mas - pergunta ele -, se não há identidade, qual seria o critério para se dizer que uma tradução é boa? Isto porque

"o critério absoluto seria o mesmo sentido, escrito em algum lugar, acima do texto de partida e de chegada e entre eles. Esse terceiro texto seria portador do sentido idêntico que supostamente circula do primeiro ao segundo [...]. Uma boa tradução só pode visar a uma equivalência presumida, não baseada numa identidade demonstrável entre sen- 
tidos, uma equivalência sem identidade" (p. 60, grifo do autor).

Aqui eu faria algumas observações que começam com um convite reiterado à adoção de uma tipologia textual mínima. Existem textos nos quais a univocidade é uma exigência sine qua non. Esses seriam os chamados textos "técnicos" ou - melhor "de especialidade", que contenham um vocabulário restrito a determinada área no qual a relação entre palavra e referente seja unívoca. Nesse tipo de texto, o "terceiro texto" poderia ser a imagem. Por exemplo, uma foto me leva à convicção de que à palavra italiana spingidisco corresponde, em português, à expressão platô de embreagem. Esse é o reino do nome, do substantivo. ${ }^{10} \mathrm{~A}$ avaliação de uma boa tradução, nesse tipo de texto, sempre se baseia no exame da identidade entre os significados de dois vocábulos (o da língua de partida e o da língua de chegada) em relação a um mesmo conceito, passando pelo conhecimento do referente (mesmo no sentido leibniziano, conforme visto acima). No que diz respeito às outras formas de texto, ou mesmo a outras partes de um mesmo texto que contenham esse tipo de vocabulário, sempre haverá margem para a avaliação por meio de uma equivalência consagrada e comprovada pelo uso, pela tradição etc., etc. O outro extremo seria o texto poético, reino da multivocidade, sobre cuja teoria seria preciso escrever um outro ensaio (uma amostra das dificuldades que esses textos costumam apresentar foi a citação de Lispector, acima). Logo, o que queremos dizer é que esse "terceiro texto" é uma hipótese idealista, irrealizável. Esse terceiro texto não existe jamais como objeto palpável. Porque esse terceiro texto é múltiplo: seu número é igual ao número de avaliadores ou críticos da tradução. Cada crítico terá em mente um texto-modelo que lhe servirá de parâmetro para a avaliação. Assim, cada avaliação deveria, em situação ideal, conter as premissas nas quais se baseou o avaliador para dizer se um texto é bom ou mau. E essas premissas jamais poderão ser traçadas sem que se leve em conta, prelimi10 Sobre essa tipologia, remeto a meu prefácio em Conversas com traduto-
res, Parábola, São Paulo, 2003. 
narmente, o tipo de texto, o seu objetivo, o público-alvo e, talvez, algumas outras coisas.

A equivalência sem identidade, propugnada por Ricoeur, é aquilo que já existe. Seria demonstrada, segundo ele mesmo, pela presença de retraduções dos grandes textos da humanidade, "em especial os que superam a barreira da disparidade dos sistemas de recorte e recomposição frástica e textual” (p. 61). ${ }^{11}$

No fim do seu último ensaio, Ricoeur se pergunta se, afinal, a questão do intraduzivel já foi esgotada. E responde que não, pois o enigma da equivalência foi resolvido com a construção da própria equivalência. Se bem entendo, malograda a busca de uma equivalência preexistente, o tradutor se vê na contingência de construir a equivalência. Constrói-se então o "comparável". E diz Paul Ricoeur:

Essa construção ocorre no nível do "sentido". "Sentido", última palavra que não comentamos, porque a presumimos. Ora, o sentido é arrancado de sua unidade com a carne das palavras, carne que se chama "letra". Os tradutores se desembaraçam dela para não serem acusados de tradução literal $[\ldots]$ Excelentes tradutores ${ }^{12}[\ldots]$ fizeram campanha contra 'apenas' o sentido sem a letra, sentido

\footnotetext{
11 Sobre o assunto da retradução, abordado de forma sistemática, além dos autores consagrados, há uma interessante publicação entre nós: a revista Cadernos de tradução $\mathrm{n}^{\circ} 11$ (PGET, UFSC, 2003). Mescladas a considerações aplicadas, é possivel depreender dos diversos artigos considerações interessantes de ordem teórico-pragmática, tais como: a preferência das grandes editoras por retraduções (em lugar de reedições de traduções antigas) porque os críticos "adotam a lógica da retradução, ou seja, a nova tradução está mais voltada para a fonte (é mais precisa, mais confiável, portanto melhor) ("Retranslation in the age of digital reproduction", Kaisa Koskinen, p. 31); a retradução por erro contido na tradução mais antiga ("retraduzir é sempre contratraduzir", segundo fórmula de Berman); a impossibilidade de traduzir o grande texto "uma vez por todas", pois cada tradução é uma interpretação, cada uma obedece a um "horizonte de expectativas" (do tradutor, de sua época etc.), que se reflete numa "posição tradutiva", e, assim, "ninguém escapa a seu tempo" ("Retraduire la Bible: le Qohélet”, Ines Oseki-Dépré) etc.

12 Berman e Meschonnic.
}

TRadTerm, 12, 2006, p. 33-54 
contra a letra. Abandonavam o abrigo confortável da equivalência do sentido e arriscavam-se nas regiões perigosas onde se tratasse de sonoridade, sabor, ritmo, intervalos, silêncio entre as palavras, métrica e rima. A imensa maioria dos tradutores resiste [...] a reconhecer que traduzir apenas o sentido é renegar uma aquisição da semiótica contemporânea, a unidade de som e sentido, significado e significante $[\ldots]$ ]" (grifos do autor).

Sobre Berman, Ricoeur ainda diz:

"a tradução 'literal' que ele busca não é uma tradução palavra por palavra, mas letra por letra [...]. Berman faria uma crítica quase desesperada da equivalência sentido por sentido.

Temos aqui finalmente três observações para fazer. A primeira diz respeito à preferência de Berman pela letra, em detrimento do sentido. A segunda observação diz respeito à comparação que nesse trecho Ricoeur faz entre Berman e Henri Meschonnic. De fato, os dois se insurgem contra a tradução do sentido sem atenção à letra. Mas o fazem de duas maneiras diferentes. São bem notórias as divergências entre ambos, e aqui não haveria espaço para me alongar nesse interessante assunto. O terceiro e último aspecto que merece destaque diz respeito especificamente ao "sentido". Fica-me a estranha impressão de que Ricoeur, nesses ensaios, deixou de lançar uma ponte entre suas reflexões sobre tradução e o restante de sua obra. Em especial em La métaphore vive (p. 91-92), ele mesmo dá a chave para a solução do impasse do qual não sai em seu De la traduction. Sempre tomando Benveniste como referência, diz:

É por meio da consideração das diferenças de nível na arquitetura da linguagem que o grande sanscritista francês introduz a distinção entre as unidades respectivas da língua e do discurso: de um lado, os signos; de outro, a frase. [...] Uma unidade lingüística qualquer só é aceita como tal se puder ser identificada numa unidade de grau superior: o fonema na palavra, a palavra na frase. A palavra está assim numa posição funcional intermediária que decorre de sua dupla natureza. De um lado, ela se decompõe em unidades fonemáticas que são de nível inferior; de 
outro, entra, na qualidade de unidade significante e com outras unidades significantes, numa unidade de nivel superior. $[\ldots]$

A unidade de nível superior é a frase, que constitui um todo que não se reduz à simples soma de suas partes. O sentido inerente desse todo está repartido pelo conjunto dos constituintes. E a palavra, como constituinte da frase, é um elemento sintagmático.

Portanto, a progressão não é linear de uma unidade à outra; surgem propriedades novas, que derivam da relação específica entre unidades de niveis diferentes; enquanto as unidades do mesmo nível têm entre si relações distribucionais, os elementos de nivel diferente têm relações integrativas.

Esse conceito é fundamental. A tradução - operação que parte do texto para a palavra (segundo o próprio Ricoeur) - desce, portanto, de niveis "superiores" - integrativos - para niveis "inferiores" - distribucionais. Logo, não é possivel continuar analisando o fenômeno da tradução com uma visão puramente distribucional (a consideração do signo como tal, de maneira estanque), mas é preciso sempre ter uma visão integrativa: a que estabelece relações complexas entre os diversos elementos (também extralingüísticos).

E o próprio Ricoeur diz isso:

A distinção desses dois tipos de relação determina a distinção entre forma e sentido: a análise distribucional no mesmo nivel depreende segmentos formais, "constituintes"; a decomposição em unidades de nivel inferior dá "integrantes", que estão numa relação de sentido com as de nivel superior. [...] a dissociação nos dá a constituição formal; a integração nos dá unidades significantes (grifo meu).

É assim que, em La Métaphore vive, em várias ocasiões, ele opõe a visão semiótica à visão semântica. De grande interesse me parece ser o trecho em que fala (p. 159-160) sobre a divisão significado-significante em Saussure.

Para ele, em Saussure há oposição entre, de um lado, a relação significante-significado e, de outro, a relação externa sig- 
no-coisa, repudiada por este. A “coisa” já não faz parte dos fatores da significação: o signo lingüístico não une uma coisa e um nome, mas um conceito e uma imagem acústica.

Essa divisão engendra uma aporia. Pois o discurso, por sua função de referência, põe, sim, os signos em relação com as coisas; a denotação é uma relação signo-coisa, enquanto a significação é uma relação significante-significado. Daí resulta uma ambigüidade da própria noção de sentido: como significado saussuriano, o sentido nada mais é que a contrapartida do significante $[\ldots]$ em relação à realidade denotada, o sentido é o mediador entre as palavras e as coisas, ou seja, aquilo pelo que as palavras se reportam às coisas [...] Ao excluir a relação sentido-coisa, a lingüística liberta-se das ciências normativas lógico-gramaticais, funda sua autonomia ao assegurar a homogeneidade de seu objeto, já que significante e significado ficam dentro das fronteiras do signo lingüistico. Mas a contrapartida é pesada. Torna-se muito difícil, senão impossivel, dar conta da função denotativa da linguagem no âmbito de uma teoria do signo que só reconheça a diferença interna entre significante e significado, ao passo que essa função denotativa não oferece nenhuma dificuldade numa concepção da linguagem que distinga de saída os signos e o discurso e que defina o discurso, ao inverso do signo, por sua relação com a realidade extralingüistica.

É aqui que nos parece haver uma desvinculação entre uma obra e outra de Ricoeur. Eu me pergunto por que Ricoeur não levou em conta estas suas considerações quando falou da tradução, considerações estas que ele faz ao tratar da metáfora. Parece-me claro que qualquer reflexão em torno da tradução que só leve em conta aquilo que ele chama de fatores semióticos redundará em aporia, a mesma aporia indicada nesse trecho. Porque a tradução a) trabalha com o discurso e b) está sempre às voltas com o referente. A tradução trabalha com denotação $e$ conotação, dialeticamente. A mente do tradutor estabelece correlações entre esses fatores todos por meio de processos cognitivos pouco conhecidos. ${ }^{13}$

13 Essa é uma das razões de a tradução por máquina não ter sido perfeitamente bem-sucedida até agora. A máquina ainda não é capaz de lidar dia- 
Parece-me evidente que as faculdades cognitivas em jogo no processo de tradução não restringem sua ação aos limites impostos pelas noções clássicas de identidade. A interação entre os diversos elementos do discurso, na forma estudada por Jakobson, Benveniste, Ricoeur e outros, é apenas a ponta do iceberg cujo corpo principal está mergulhado num mar de profundezas pouco exploradas até agora. E é provável que esse mar não exclua alguma espécie de contradição (nos termos clássicos), em que o texto traduzido é e não é, ao mesmo tempo, o texto original.

\section{Referências bibliográficas}

ABBAGNANO, N. (1998) Dizionario di filosofia. Torino: UTET, $3^{\text {a }}$ ed. BENVENISTE, É. (1995) Problemas de lingüistica geral. Trad. Maria da Glória Novak e Maria Luísa Neri. Campinas: Pontes.

ECO, U. (2000) Os limites da interpretação. S. Paulo: Perspectiva, trad. Pérola de Carvalho.

JAKOBSON, R. (1969) Lingüística e comunicação. Trad. Isidoro Blikstein e José Paulo Paes. São Paulo: Cultrix.

RICOEUR, P. (1975) La Métaphore vive. Éditions du Seuil. . (2004) Sur la traduction. Paris: Bayard.

leticamente com o discurso em seu todo, ou seja, com as relações entre texto, referente e a rede de inferências que, no cérebro do tradutor, é criada pela interação de todos esses elementos e de outros elementos extratextuais. Prova disso é que todas as empresas que trabalham com tradução "assistida", num processo em que os termos já traduzidos e armazenados deixam de ser pagos, para conseguirem armazenar o máximo de dados e assim baratear os serviços de tradução, fazem questão de reduzir o discurso às suas feições mais simples: simplicidade sintática, em que a ordem frasal obedeça ao esquema convencional SN + SV, nessa ordem, e univocidade (as palavras empregadas não podem dar ensejo a mais de uma interpretação). 